* Doutorado em Direito pela Universidade Federal de Minas Gerais, Brasil (2007). COORDENADOR DA PESQ.- PROJ. CIDADE ALTERIDADE da Fundação Universidade de Itaúna, Brasil. E-mail: eloy.junior @ uol.com.br

** Pós-Graduando em Direito Material e Processual do Trabalho pela Faculdade de Direito Professor Damásio de Jesus. E-mail: raul.vasconcelos@hotmail.com

\section{Reorganização societária e blindagem patrimonial por meio de constituição de holding}

\section{CorPorate RESTRUCTURING AND SHIELD SHEET THROUGH THE CONSTITUTION OF HOLDING}

\author{
* Eloy Pereira Lemos Junior \\ ** Raul Sebastião Vasconcelos Silva
}

Resumo: É característica do empreendedorismo a absorção de benesses bem como a assunção de riscos inerentes ao seu exercício. Nesse sentido, natural optar por formas mais rentáveis na sua gestão, se utilizando de mecanismos que proporcionem segurança jurídica e patrimonial no deslinde das atividades. Nessa esteira, destaca-se a figura da Holding, forma de se reestruturar o quadro societário, blindar o patrimônio e otimizar a carga tributária. Tal desígnio abarca a forma lícita de se planejar a redução de custos, organizar o empreendimento e estruturar a sociedade. No presente artigo serão apresentadas diretrizes que norteiam tal instituto, abordando suas peculiaridades e implicações.

Palavras-chave: Holding; Reestruturação societária; Blindagem patrimonial.

Abstract: It is characteristic of entrepreneurship absorption handouts as well as the assumption of risk inherent in its exercise. In this sense, opt for natural ways most profitable in its management, is using mechanisms that provide legal certainty and equity in disentangling the activities. On this track, there is the figure of the holding company, way to restructure the shareholding structure, shielding the assets and optimize the tax burden. This plan includes the lawful plan to reduce costs, organize and structure the enterprise society. In the present article shall be given guidelines by which such an institute, addressing their peculiarities and implications.

Keywords: Holding; Corporate Restructuring; Asset Shield. 


\section{INTRODUÇÃO}

No Brasil, o empreendedor que opta pelo desenvolvimento de alguma atividade empresária, o faz, geralmente, associado a outrem na modalidade societária. Dentre estas, destaca-se, como a de maior predileção do empresariado nacional a figura da sociedade empresária limitada.

A facilidade de se constituir uma sociedade empresária limitada, associada aos seus baixos custos e à responsabilização restrita do sócio vinculada ao quantum investido em capital atraem os empreendedores pátrios.

Assim, em tese, com a constituição de uma sociedade empresária limitada ocorre a segregação patrimonial, havendo distinção entre os bens pertencentes à pessoa jurídica e ao sócio enquanto pessoa natural.

Dito isso, nada mais natural do que a sensação que ladeia o imaginário de nossos empresários, que ao adotarem a figura em tela, pensam estar plenamente resguardados. Ledo engano.

Ainda que pese a distinção patrimonial e responsabilização fixada aos limites do capital investido, existem exceções consideráveis a esta regra.

Ademais, encargos que beiram a extorsão somados às nuances mercadológicas colocam, sob risco constante, a manutenção da sociedade.

Por vezes, a incidência desses encargos somada à ausência de planejamento, ou à sua má realização, resultam no insucesso empresarial. Nessas situações verifica-se que os gastos dispêndios com o exercício social se tornaram deveras onerosos, suplantando o faturamento percebido.

É nesse sentido que surge o instituto do planejamento empresarial, abrangendo as esferas societária, tributária e patrimonial.

Tal diretiva, se realizada de forma lícita, em observância à legislação em vigor, é maneira eficaz de se blindar o patrimônio titularizado, garantindo, desse modo, o principio da preservação empresarial.

Destarte, a reorganização societária realizada à luz das diretrizes legais se mostra como importante ferramenta ao empresário, de modo a proporcionarlhe 5 maior segurança jurídica, bem como promover a blindagem de seu patrimônio e prover outras benesses.

\section{HOLDING - CONCEITO DE HOLDING}

O termo Holding tem origem estrangeira, sendo oriundo da língua inglesa e significando segurar, manter, controlar, guardar. Tal terminologia faz alusão à 
sua finalidade, ou melhor, ao seu objeto social que é, em suma, o controle e a participação em outras sociedades empresariais ou, ainda, "segurar" ou "manter" a administração de bens, geralmente imóveis.

Segundo dispõe o vernáculo, Holding tem por definição "Companhia que, sem atividade produtora própria, possui número de ações suficientemente grande de outras companhias, o que lhe assegura o controle das habilitações comerciais destas". É o que nos diz o Dicionário Michaelis (MICHAELIS, 2013). Todavia, sua terminologia jurídica é mais ampla e abarca um sentido mais claro do que realmente significa o dito termo.

Analisando exclusivamente sob o aspecto funcional, a Holding, que é o instituto mais moderno (e legal) para proteção patrimonial (física e jurídica), é constituída, quase sempre, com o fim de participar de outras sociedades como quotista ou acionista, controlando-as.

As holdings geralmente são constituídas por empresários que detêm várias empresas, que atuam em diversos nichos de atividades, sendo que, por muitas vezes, isto é feito para se evitar a concentração do capital em apenas um setor.

A figura da Holding, inicialmente pré-julgada como uma inovação jurídica suficiente a burlar a legislação, tornou-se comum com o avanço do mercado, tornando-se até mesmo padrão para grandes grupos econômicos. Ademais, a Holding se tornou uma estrutura vantajosa com o advento do novo Código Civil, quando se expandiram sobremaneira as possibilidades legais de despersonalização da personalidade jurídica, que pode imputar aos sócios a responsabilidade e o dever de suportar com seu próprio patrimônio as dívidas da pessoa jurídica.

Por fim, insta ressaltar que a Holding, ainda que pese todas as características que lhe são inerentes, é uma empresa semelhante às demais, se submetendo às mesmas diretrizes legais impostas às outras pessoas jurídicas, distinguindo-se por seu objeto social e filosofia.

\section{NATUREZAJURÍDICA}

Ao empresário que optar pela constituição da Holding será facultado a escolha do tipo societário que melhor lhe convier conforme sua necessidade. Isto significa que a holding pode assumir a modalidade de "Sociedade Limitada", "Sociedade Simples", "Sociedade Anônima”, "Eireli” ou qualquer outra espécie de personalidade jurídica prevista em na legislação nacional. 
Tal decisão, opção pela natureza jurídica, deve levar em consideração as características do caso concreto, vez que a referida escolha se encontra diretamente vinculada à destinação para qual a Holding foi constituída.

Desse modo destaca-se a predileção nacional pelas figuras que imputam responsabilidade limitada aos sócios. Dentre estas, podemos destacar ainda a sociedade anônima, que conta com previsão expressa no sentido de ser uma Holding em sua legislação própria.

Importante ressaltar ainda a inovação trazida à luz em nosso Código Civil com a criação da figura da Eireli - Empresa Individual de Responsabilidade Limitada, que surge como mais uma opção ao empresário, que poderá constituir a Holding sem a necessidade de contar com sócio, desde que preenchendo os requisitos legais.

Por fim, se faz pertinente a menção de que tanto pessoas físicas quanto jurídicas podem compor o quadro societário de uma Holding, excetuando-se, por óbvio, as ressalvas dispostas por nosso ordenamento. Cabe frisar que tal regra encontra exceção nos casos de Eireli, cuja titularidade é vedada à pessoa jurídica. Ademais, é limitado à pessoa física ser titular de apenas uma Eireli.

\section{PREVISÃO LEGAL}

No Brasil, o instituto da Holding foi inserido na legislável com o advento do artigo $2^{\circ}$ da Lei $n^{\circ} 6.404$ de 1976, também conhecida como a "Lei das S/A.". Neste mesmo diploma podem ser encontradas ainda outras diversas menções às Holdings, 7 tais como as decorrentes do artigo 243, cuja redação prevê situações peculiares e imputa obrigações específicas a essa inovação jurídica.

Contudo, tais previsões não se resumem apenas à Lei das S/A., existindo também no Código Civil Nacional, mormente em seu capítulo que trata as Sociedades Coligadas, que abrange os artigos 1.097 e seguintes.

Destarte, tem-se que com a utilização dos instrumentos legais disponíveis no ordenamento jurídico nacional, é possível realizar uma melhor organização das atividades empresariais, efetuando a separação e organização das atividades e bens empresariais das pessoais, com escopo de se proteger de situações externas, bem como reduzir a carga incidente sobre tais negócios, entre outras finalidades.

Assim, resta caracterizado, uma vez mais, tratar-se de tema atual, pautado em diretrizes legais e, por conseguinte, lícito, desmistificando qualquer suspeita que possa pairar sobre o instituto Holding. 


\section{CLASSIFICAÇÃO}

Insta trazer à baila que as Holdings, no ordenamento pátrio brasileiro atual, são costumeiramente divididas em duas espécies, quais sejam:

a) Holdings puras: cuja principal característica é o exercício de atividade exclusiva de controle de outras sociedades, tendo suas receitas privativas de lucros e dividendos das empresas controladas.

b) Holdings operacionais: não obstante ao fato de deterem características semelhantes às encontradas nas Holdings puras, distinguem-se das primeiras por possuírem também outras atividades operacionais, tais como a prestação de serviços.

Entretanto, necessário destacar que, apesar de comum, a distinção supratranscrita não é a única apresentada em nossa doutrina. Existem outras diversas classificações, cujo critério para sua estruturação baseia-se na finalidade para qual a pessoa jurídica foi constituída. Vejamos alguns exemplos:

a) Holdings de controle: detêm por escopo assegurar o controle de empresas.

b) Holding administrativa: visa a função administrativa das empresas operadoras; 8.

c) Holding familiar: objetiva evitar os núcleos familiares, evitando possíveis conflitos de interesses.

\section{DESCONSIDERAÇÃO DA PERSONALIDADE JURÍDICA}

A priori, deve ser ressaltado que a figura da personalidade jurídica caracteriza-se por inovação pautada em ficção jurídica, constituída com fulcro na promoção de autonomia à empresa na consecução de seu objeto social.

Isso posto, destaque-se ainda que empreender é assumir riscos inerentes à atividade exercida. Por essa premissa, o empresário deve entender que o exercício de suas atividades empresarias implica, necessariamente, na absorção de todos os benefícios que dela possam ser oriundos, bem como em suportar os dissabores surgidos dessa relação.

Assim, tem-se que a dita autonomia não é soberana, vez que os atos praticados pela pessoa jurídica estão vinculados à vontade de seus sócios diretores.

Nessa esteira, importante mencionar que com o advento das novas legislações pátrias, em especial o atual Código Civil Brasileiro, a restrição da 
obrigação delimitada ao capital investido, outrora protegida sob a égide da figura empresarial de responsabilidade limitada, deixou de ser absoluta.

Desse modo, consonante a moderna legislação nacional vigente, o empresário que transgredir determinadas premissas poderá incorrer no ônus de suportar o adimplemento de obrigações com seu patrimônio pessoal.

A este fenômeno dá-se o nome de Desconsideração da Personalidade Jurídica. O mesmo ocorrerá todas as vezes que restar por caracterizado o desvio da finalidade para qual foi constituída a empresa e houver a confusão patrimonial entre os bens sociais e particulares.

Em suma, o que se objetiva com a utilização da dita ferramenta é coibir fraudes na medida em que tal instituto afasta a segregação patrimonial existente entre sociedade e sócio. Ao tornar os patrimônios outrora distintos numa universalidade, tal desígnio visa punir os excessos cometidos pelo mau empresário e salvaguardar os direitos dos credores de boa-fé. 9

\section{HIPÓTESES DE DESCONSIDERAÇÃO DA PERSONALIDADE JURÍDICA}

A teoria da desconsideração da personalidade jurídica, originariamente cunhada como "disregard of legal entity", recebe esse nome devido à sua origem jurisprudencial inglesa e norte americana. Sua incidência ocorrerá sempre que restar caracterizada qualquer das seguintes hipóteses:

a) Abuso: caracteriza-se pelo excesso cometido pelo empresário no exercício de suas atividades empresariais. Em ocorrendo, o autor incorre em transgressão legal a dispositivo expresso em lei;

b) Fraude: subterfúgio utilizado com fulcro na transgressão legal, bem como na promoção de prejuízos deliberados à terceiros. Para Maria Helena Diniz, "Constitui fraude contra credores a prática maliciosa, pelo devedor, de atos que desfalcam o seu patrimônio, com o escopo de colocá-lo a salvo de uma execução por dívidas em detrimento dos direitos creditórios alheios (DINIZ, 2005)".

c) Desvio de finalidade: inobservância do objeto social precípuo para o qual a empresa foi constituída;

d) Confusão patrimonial: decorrente de situações em que o próprio sócio é incapaz de tratar o patrimonio social como alheio, ocorrendo, por conseguinte, confusão que invibializa a distinção patrimonial.

Assim, consoante preceitua nosso Código Civil, mormente em seu artigo 50, havendo, comprovadamente, o abuso da personalidade jurídica, seja pelo 
desvio de finalidade, seja pela confusão patrimonial ou caracterização de fraude, poderá o judiciário decidir para que os efeitos de determinadas relações obrigacionais gerem consequências junto aos bens do particular.

No mais, não obstante às hipóteses descritas, é matéria pacificada em nosso ordenamento pátrio a possibilidade de se atribuir a responsabilidade patrimonial aos sócios da empresa em se tratando de demandas atreladas ao Código de Defesa do Consumidor, ao Direito Ambiental, em algumas espécies de execuções fisscais e ainda a solidariedade na justiça do trabalho. Cabe ressaltar que no âmago 10 trabalhista se considera o princípio da proteção máxima ao empregado em detrimento ao empregador. Tal situação, por óbvio, ocasiona certos exageros que se consubstanciam até mesmo em abusos no plano fático.

Há de se ressaltar ainda que a incidência da desconsideração pode ser aplicada independentemente do tipo societário e natureza jurídica da empresa. Incorrendo, inclusive, em sociedade cuja responsabilidade em tese é limitada.

Outro ponto importante que denota atenção especial é a necessidade do apoio jurisdicional do Estado para ver aplicada a desconsideração. Tal medida não será tomada administrativamente.

Por fim, insta frisar que ocorrendo a desconsideração, não necessariamente haverá a extinção da personalidade jurídica da empresa que deu causa ao pedido. Tal instituto tem caráter transitório e visa somente resguardar o direito do credor.

\section{REESTRUTURAÇÃO SOCIETÁRIA}

A reestruturação consiste numa sequência de medidas realizadas com fulcro na formatação e equalização de uma nova estrutura societária para a empresa / grupo empresarial.

À Luz do vernáculo, conforme aduz o conceituado Dicionário Michaelis (2013), reestruturar é "dar nova estrutura a; reestabelecer, organizar de novo". Assim, fácil notar que reestruturar, no âmbito para o qual o definimos, diz respeito à adoção de uma série de meios lícitos com intuito de promoção de finalidade legal, qual seja: blindagem patrimonial.

Tal diretriz é plenamente facultada ao empresário, ao passo que não lhe é obrigada a assunção de estrutura deveras dispendiosa. Desse modo, vislumbrase aqui uma série de medidas legítimas, vez que pautadas na lisura.

Ademais, tem-se que a reestruturação em voga pode promover também uma reorganização tributária, maximizando a carga, sempre que possível. 
Todavia, importante ressaltar que a constituição de Holdings não é a única forma de se reestruturar o quadro societário, bem como maximizar a carga de uma empresa/grupo empresarial. Existem ainda outros mecanismos no mesmo sentido, que serão explorados no tópico a seguir.

\section{TRANSFORMAÇÃO, FUSÃO, INCORPORAÇÃO E CISÃO}

Consoante dito anteriormente, há outras possibilidades legais para realização da reestruturação societária. Dentre estas, destacam-se as figuras da transformação, fusão e incorporação.

A transformação de sociedade, que é um desses institutos, conta com previsão expressa na legislação pátria. O dispositivo 220 da Lei 6.404/76 define claramente a transformação societária como "a operação pela qual a sociedade passa independentemente de dissolução e liquidação, de um tipo para outro". Para Modesto Carvalhosa (2002) na transformação "não existe dissolução ou liquidação da 12 pessoa jurídica, mas sim extinção dos atos constitutivos, que são substituídos por outros 2".

Outra possibilidade facultada ao empreendedor consiste na fusão, que segundo ensina a doutrina dominante se traduz na combinação de duas empresas para a formação de uma única. Vale ressaltar que nossa legislável em vigor também faz alusão ao dito desígnio. $\mathrm{O}$ artigo 228 da Lei ${ }^{\circ}$ 6.404/76 define que a fusão é a "operação pela qual se unem duas ou mais sociedades para formar sociedade nova, que lhes sucederá em todos os direitos e obrigações". No mesmo sentido, coaduna o nosso Novo Código Civil. Segundo preceitua o dispositivo $\mathrm{n}^{\circ} 1.119$ da Lei 10.406 de 2002: "a fusão determina a extinção das sociedades que se unem, para formar sociedade nova, que a elas sucederá nos direitos e obrigações".

No mais, outro meio muito difundido em nosso ordenamento cujo cerne constitui a promoção de reestruturação societária é o instituto da incorporação. Em ocorrendo, a pessoa jurídica incorporada passa a inexistir, entretanto, a empresa incorporadora continuará com a sua personalidade jurídica, diferentemente do que ocorre na fusão, em que há a extinção de todas as pessoas jurídicas participantes do processo, bem como a criação de uma nova empresa que sucede às demais.

Segundo o artigo 227 da Lei das S/A, a incorporação se caracteriza como "a operação pela qual uma ou mais sociedades são absorvidas por outra, que lhe sucede em todos os direitos e obrigações". Em sentido próximo, aduz o 
nosso Código Civil, no artigo 1.116, alegando ser patente na incorporação a absorção de uma ou várias sociedades por outra, que lhes sucederá em direitos e obrigações.

Por fim, há de se destacar ainda o instituto da cisão, que para Modesto Carvalhosa (2002, p. 305) "constitui negócio plurilateral, que tem como finalidade a separação do patrimônio social em parcelas para a constituição ou integração destas em sociedades novas ou existentes 3".

Assim, ainda que sucintamente, foram levantadas outras formas de reestruturação afora a Holding, que no presente estudo é o foco principal. 13

\section{DA REESTRUTURAÇÃO SOCIETÁRIA}

Ciente das benesses e inconvenientes que ladeiam a reestruturação, ao empreendedor cabe, devidamente assessorado por profissionais qualificados, proceder juízo de valores acerca da viabilidade de sua realização efetiva.

Por óbvio algumas reflexões devem ser realizadas de modo a se maximizar os benefícios extraídos da reestruturação por meio de Holdings. Cabe levar em consideração a análise de sua real necessidade, bem como constituir o modelo mais adequado à realidade fática apresentada. Assim, após conjecturar acerca das possibilidades e suas implicações, o empresário deve de fato iniciar o processo de reestruturação. Este, por sua vez, irá variar conforme política adotada, cabendo, ao efetua-lo, observar as idiossincrasias inerentes à sua realização.

Mister trazer à baila que, assim como qualquer outro procedimento jurídico contábil, o processo de reestruturação deve ser balizado pela licitude, não havendo excessos que o desabone e nem lhe tire a validade, bem como a eficácia perante terceiros e, principalmente, o fisco.

É nesse sentido que ensina Marco Aurélio Greco (2011, p. 120) ao discorrer sobre o procedimento em AP reço, aduzindo que "em suma, o núcleo do tema é a eficácia fiscal dos atos ou negócios jurídicos realizados, vale dizer "não basta ser lícito, é preciso ser eficaz perante o fisco'4".

Importante mencionar que o presente planejamento tem por escopo a blindagem patrimonial bem como todas as benesses que dela decorrem. Assim, necessário atender às diretrizes legais, mormente as impostas pelo fisco, uma vez que o mesmo pode desconsiderar todo procedimento realizado em casos em que restem por caracterizado simulação com escopo de promover fraude. 


\section{FORMA DE INTEGRALIZAÇÃO DO CAPITAL SOCIAL}

Como bem sabido, o capital social é o importe condicionado à viabilização de constituição da pessoa jurídica, de modo a possibilitar que a mesma inicie o 14 exercício de suas atividades. Tal importância deve ser definida consoante planejamento estipulado pelos sócios, acionistas ou titular da pessoa jurídica.

Esta integralização nada mais é do que a inserção da proporção de capital cujo cada um dos sócios, acionistas ou titular se comprometeram a ingressar na empresa. Tal integralização, salvo exceções, pode ocorrer em moeda corrente, direitos e bens, tais como imóveis, veículos e equipamentos.

Frise-se que a legislação, no que tange ao plano societário e tributário, faculta às pessoas físicas o direito de realizar a integralização de capital em bens e direitos conforme valores dispostos na Declaração de Bens ou pelo valor de mercado.

Outro ponto importante a se mencionar é o fato de que nossa Magna Carta, em seu dispositivo de $\mathrm{n}^{\circ} 156, \S 2^{\circ}$, inciso I, também estabelece, na hipótese de integralização de capital social em bens imóveis, a isenção do Imposto de Transmissão Inter Vivos (ITBI) de competência dos municípios.

Tal benesse deve ser pleiteada por meio de processo administrativo a ser demandado perante a municipalidade do local de situação do imóvel integralizado, sendo certo que a isenção somente será concedida e mantida se a receita obtida com aluguel ou com a venda dos imóveis integralizados não ultrapassar $50 \%$ (cinquenta por cento) do faturamento total da Holding durante os três anos seguintes à integralização do imóvel.

\section{BENESSES DECORRENTES DA REESTRUTURAÇÃO SOCIETÁRIA}

Conforme externado, o exercício da atividade empresarial implica na assunção de diversos riscos inerentes ao seu desempenho. Assim, a sociedade que conta com seu quadro societário titularizado única e exclusivamente por sócios pessoas físicas, poderá experimentar o dissabor de ver suas dívidas de ordem tributária, civil, ambiental e trabalhista suportadas pelo patrimônio particular de seus sócios, acionistas ou titulares, através de responsabilidade solidária.

A inserção da Holding na cadeia societária tem o intuito de resguardar a empresa da incidência de eventuais problemas, bem como já criar o ideal 
sucessório aos sócios, acionistas ou titulares, pois, conforme apurado, grande causa de cisões 15 e extinções de empresas consiste no aspecto familiar e sucessório que poderá impedir a celebração de quaisquer negociações financeiras e administrativas.

Ante o que fora apresentado, tem-se que a retirada das figuras dos sócios Pessoas Físicas do quadro societário das empresas, inserindo, em substituição, o instituto das Holdings, protege o patrimônio existente, reduzindo a carga tributária, quando possível, e elaborando o ideal sucessório.

Impende demonstrar que a Holding, como registrado, tem por escopo exercer o controle sobre um grupo de empresas, administrando ou participando de forma total ou parcial de seus respectivos capitais sociais.

Assim, resumidamente, as Holdings são constituídas com fulcro a causar dinamismo e modernidade a empresa/grupo empresarial, afora a promoção de segurança ao patrimônio de seus sócios, acionistas ou titulares. Outro grande benefício, frise-se, é a faculdade de se efetuar um planejamento sucessório das atividades mercantis, de seus bens e do patrimônio familiar, visando antecipar, de forma segura, preestabelecida e menos onerosa, a sucessão da administração empresarial, bem como dos bens.

No caso de um grupo de empresas familiar, por exemplo, ao estabelecer uma Holding controladora, a sucessão dos negócios da família se darão somente pela transferência aos herdeiros das quotas de capital/ações desta Holding, sem que haja a necessidade de mudanças societárias em todo o grupo de empresas controladas, situação que, por óbvio, proporciona maior comodidade, reduzindo gastos e procedimentos burocráticos. Tal medida facilita a transição de poderes entre os sócios quotistas/acionistas, não interferindo nos negócios do grupo empresarial e diminuindo o tempo e dispêndio, como já descrito.

\section{DESVANTAGENS DECORRENTES DA UTILIZAÇÃO DA FIGURA HOLDING}

Não obstante às benesses apontadas, a reestruturação mediante inserção de holdings na cadeia societária implica na absorção de alguns inconvenientes. Sobre gastos, evidentemente, o procedimento de constituição das empresas holdings, bem como os custos inerentes à realização de suas devidas obrigações acessórias oneram o processo de reestruturação, proteção e blindagem patrimonial. 16 
Quanto às aconselháveis transferências imobiliárias, visando promoção de blindagem patrimonial, por óbvio, gerarão, ao mínimo, custos cartorários. No que tange à tributação da atividade de locação, incidente nos casos em que a Holding locar patrimônio à empresa do grupo, o ideal é que esta seja feita em valores mínimos, visando reduzir a carga. Entretanto, a locação e o recolhimento dos tributos, afastam, ainda mais, a possível arguição de fraude.

Cabe ressaltar ainda que algumas das principais desvantagens restringemse à figura da sociedade anônima, vez que mais dispendioso e burocrático o seu trato diuturno. Dentre estas destacamos a publicação das assembleias e balanços, bem como a divulgação de informações por meios públicos, com fulcro na publicidade.

\section{POSSIBILIDADES DE DESCONSIDERAÇÃO DA REESTRUTURAÇÃO SOCIETÁRIA}

Restando comprovado a caracterização de simulação no procedimento de reestruturação, poderá restar caracterizada fraude, resultando a nulidade dos os atos suspeitos realizados. Nesse sentido aduz a legislável em vigor que, dentre outros, apresenta o dispositivo de n. 167 acerca do tema em nosso do Código Civil.

A negociação simulada se caracteriza pela existência de duas condutas, a que se pratica e a que se oculta. Tal comportamento geralmente decorre da vontade dos signatários de ser esquivar da real tributação que deveria ser atribuída ao negócio, que geralmente é mais onerosa.

Todavia, a simulação não é a única situação que pode desabonar o procedimento de reestruturação. Insta frisar que qualquer conduta ilícita é capaz de macular todo o procedimento reestruturador, conforme preceitua nosso Código Civil através de seu artigo 187.

Em suma, foram apresentadas algumas das possibilidades de desconsideração do procedimento, vez que por corolário de atos ilícitos. Destarte, restando caracterizada tal situação, quedara-se o procedimento de reestruturação inócuo, vez que eivado de vício. 17.

\section{ASPECTOS TRIBUTÁRIOS}

Com o advento da Constituição Cidadã, passou o Sistema Tributário Nacional a ser delimitado pelas diretrizes trazidas à luz pela própria Carta Magna 
em seus artigos 145 a 162, os quais tratam, em suma, de definição dos tributos e competências dos entes da Federação; limitação ao poder de tributar; e repartição das rendas tributárias. Destaque-se ainda a classificação prolatada pelo referido diploma legal, que em seu dispositivo $5^{\circ}$ aduz serem os tributos divididos em "impostos, taxas e contribuições de melhoria".

Todavia, tal diretiva não chegou a conceituar tributo. Essa aptidão foi incumbida à Lei n. 5.172/1966, que em seu artigo $3^{\circ}$ aduz ser tributo "toda prestação pecuniária compulsória, em moeda ou cujo valor nela se possa exprimir, que não constitua sanção de ato ilícito, instituída em lei e cobrada mediante atividade administrativa plenamente vinculada".

Há de se ressaltar que sua incidência não decorre de sanção oriunda de ato ilícito, vez que sua origem sucede de previsão institucional, devidamente validada conforme preceitos do principio da legalidade.

Contudo, é possível vislumbrar ainda na carta constituinte, através de análise de seu dispositivo de n. 149, autorização concedida à União para estabelecer contribuições federais sociais e de intervenção no domínio econômico, findando numa nova espécie tributária.

Se não fosse suficiente, ao analisar a legislável brasileira verifica-se ainda previsão expressa de outra modalidade tributária, qual seja: empréstimo compulsório. Tal disposição decorre do artigo 148 da Constituição Republicana, que aduz que a "União, mediante lei complementar, poderá instituir empréstimos compulsórios”. Destarte, vislumbra-se que os tributos, conforme previsão constitucional e legal, dividem-se em cinco espécies, quais sejam: impostos, taxas, contribuição de melhoria, contribuição especiais e empréstimos compulsórios.

Ante o grande número de espécies tributárias num país como o Brasil, detentor de vasto território, a solução encontrada para dirimir dúvidas e confusões relativas ao poder de tributar foram estabelecidas com a instituição da figura da 18 competência tributária. Assim, se verificam diferenciações entre União, Estados, Distrito Federal e Municípios. Logo, não podendo ocorrer interferência de uns sobre os outros, ficando cada qual adstrito à sua competência originária preestabelecida.

Cabe frisar que a competência tributária também varia conforme natureza do tributo e atribuição do ente federado.

Destarte, ante a breve exposição supra relatada, verifica-se que a despesa tributária nacional caracteriza-se como um dos principais "custos de produção" de um empreendimento. Sendo assim, faz-se indispensável reduzir tal dispêndio 
tributário de forma legal, visando a maximização dos resultados econômicofinanceiros das empresas, tornando-as mais robustas e competitivas. É nesse sentido que se apresenta a reestruturação societária.

\section{ASPECTOS TRIBUTÁRIOS PÓS REESTRUTURAÇÃO - HOLDING}

Colocadas as diretivas iniciais acerca da questão tributária, passemos analisar, pormenorizadamente, o aspecto fático que incidirá sobre a Holding.

Tributação Incidente Sobre os Resultados Contábeis Apurados - Holding

Os critérios de tributação incidentes sobre a receita da Holding variam conforme escopo social da empresa. Nos casos de Holding pura, esses valores não sofrerão tributação pela sociedade controladora. No que tange à Holding mista, que além do exercício de atividades de controle, semelhantes às realizadas pela Holding pura, efetuam também operações de natureza diversa, bem assim no que se refere aos ganhos de capital, serão imputadas as diretrizes tributárias específicas para o regime escolhido pela controladora (lucro real, presumido ou arbitrado).

Recebimento de Lucros e Dividendos - Holding 19

No que concerne ao recebimento de lucros e investimentos, importante mencionar que os lucros ou dividendos percebidos pela Holding, em decorrência de participação societária avaliada pelo custo de aquisição, adquirida até 6 (seis) meses anteriores à data do devido recebimento, serão, contudo, registrados pela empresa como diminuição do valor do custo e não incidirão nas contas de resultado.

Capitalização de Lucros ou Reservas - Holding

As ações ou quotas bonificadas, percebidas sem ônus pela Holding, não incidirão alteração no importe pelo qual a participação estiver registrada no ativo, nem serão levadas em consideração na estipulação do lucro real. Tal diretriz é aplicável à luz da legislável em vigor. Mormente pelo artigo $381 \mathrm{e}$ seguintes do Decreto n ${ }^{\text {3 } 3.000 / 1999 . ~}$

Distribuição de Lucros e Dividendos - Holding

O ativo e passivo apurado no resultado contábil da Holding, creditado por pessoa jurídica com base na tributação lucro real, desde janeiro de 1996, 
não se sujeita à incidência do imposto de renda na fonte, bem como não se vincula à base de cálculo do imposto do beneficiário, seja pessoa jurídica ou física, domiciliado em território nacional ou no exterior. Tal diretiva é trazida à luz pelo artigo 654 do Decreto n. 3.000, de 26 de março de 1999. Vale ressaltar que em sentido próximo surgem também os dispositivos de n. 662 e 666 do mesmo diploma legal.

Deferimento de Despesas Financeiras - Holding 20

Consoante previsão legal, à Holding que detenha por objeto apenas a participação societária em outras empresas, será facultado o diferimento do reconhecimento de despesas com juros e encargos financeiros pagos ou incorridos relativos a empréstimos contraídos para financiamento de investimentos em sociedades controladas. É o que nos diz a Lei n ${ }^{\circ} 11.727 / 2008$.

Insta salientar que tal benesse é aplicável somente às Holdings "puras", quais sejam, as criadas com fulcro em participações societárias. Destarte, não incidirão sobre as Holdings "mistas", que não se atêm exclusivamente às atividades de controle, desenvolvendo também operações de natureza diversa.

\section{DISSOLUÇÃO}

Consoante amplamente externado, a Holding é empresa como qualquer outra, diferenciando-se, apenas, pelo objeto social que lhe é peculiar.

Destarte, há de se verificar que as suas hipóteses de dissolução são as mesmas aplicadas às demais empresas. Tais diretivas são apresentadas em nosso sistema legal, pelo Código Civil, no artigo 1.033 e seguintes.

No que concerne às Holdings cuja natureza jurídica se consubstancia em sociedade anônima, há regimento próprio para tal procedimento, previsto na Lei das S/A, dentre os artigos 206 à 219.

De todo modo, o procedimento de baixa poderá variar conforme localização geográfica da Holding em território nacional, vez que as exigências das Juntas Comerciais, apesar de bastante semelhantes, não são idênticas.

Outro ponto importante a ser ressaltado, é o fato de que a competência para registro do distrato de algumas Holdings, cuja natureza jurídica seja de sociedade simples, não cabe às Juntas Comerciais, mas sim aos Cartórios de Registro de Pessoa Jurídica da comarca onde se estabelece a Holding. Por tal motivo, o processo de baixa deve tramitar junto a tal instituição, sujeitando-se às suas exigências legais para registro. 
Posteriormente, com o distrato social devidamente registrado, cabe ao empreendedor regularizar a situação de baixa da Holding junto aos competentes órgãos públicos e particulares, tais como a fazenda federal, fisco municipal, previdenciário e entidades correlatas cuja empresa detinha cadastro.

\section{CONSIDERAÇÕES FINAIS}

À luz da realidade fática experimentada pelo empreendedor nacional, fácil notar o quão oneroso é exercer a atividade empresarial no Brasil. A obscena carga tributária somada aos altos encargos trabalhistas e às nuances inerentes ao cotidiano mercadológico aumentam sobremaneira tal risco.

O exercício empresarial pura e simplesmente, figura indissociável a promoção do empreendimento, todavia, não representa garantia de êxito na empreitada. No plano real, possível notar que diversos empresários, no afã de fomentar suas atividades, por não deterem planejamento adequado a tal, não suportam as intempéries as quais são submetidos.

Nessa esteira, faz-se imprescindível o planejamento empresarial, bem como a blindagem patrimonial e estruturação societária, de modo a otimizar as receitas, protegendo os ativos e minimizando a carga tributária.

Destarte, fácil notar que o aumento do grau de profissionalização do empresariado tornou-se necessidade premente ao empreendedorismo. Entretanto, há de se ressaltar que tal diretriz deve-se pautar pela legalidade.

No que tange ao planejamento, deve-se levar em consideração a diretiva da boa-fé objetiva, bem como as vicissitudes que dela decorrem, de modo a se evitar a sua realização de forma abusiva ou ilícita.

No mesmo sentido caminha a blindagem patrimonial, que pautada nas disposições legais, continuará proporcionando à empresa/grupo empresarial beneficiários de sua efetivação, o cumprimento da competente função social.

No trabalho em apreço não se quis promover condutas ilícitas com fulcro no abuso ou transgressão legal de modo a caracterizar fraudes a ordem em vigor. O que pleiteamos foi a tomada de medidas legais objetivando planejamento empresarial e a conseguinte blindagem patrimonial.

Tal faculdade caracteriza-se como direito subjetivo ao empresariado nacional, ao qual não é imputado o dever de arcar com o modelo empresarial/ tributário mais arriscado e dispendioso. 


\section{REFERÊNCIAS}

BRASIL. Constituição (1988). Constituição da República Federativa do Brasil. Palácio do planalto. Disponível em:<http://www.planalto.gov.br/ ccivil_03/ constituicao/constituicaocompilado.htm>. Acesso em: 30 mar. 2013.

CARVALHOSA, Modesto. Comentários à lei de sociedade anônima: Lei $n^{\circ} .6 .404$, de 15 de dezembro de 1976, com as modificações das Leis $n^{\circ}$. 9.457, de 5 de maio de 1997, e n ${ }^{\circ} .10 .303$, de 31 de outubro de 2001. São Paulo: Saraiva, 2002.

DINIZ, Maria Helena. Curso de Direito Civil Brasileiro. 22. ed. São Paulo: Saraiva, 2005.

GRECO, Marco Aurélio. Planejamento tributário. 3. ed. São Paulo: Dialética, 2011.

MICHAELIS. Dicionário online. UOL. Disponível em: <http:// michaelis.uol.com.br/>. Acesso em: 26 mar. 2013.

Submetido em: 14/07/2013 Aprovado em: 17/11/2014

Como citar: LEMOS Jr, Eloy Pereira; SILVA, Raul Sebastião Vasconcelos. Reorganização societária e blindagem patrimonial por meio de constituição de holding. Scientia Iuris, Londrina, v.18, n.2, p.55-71, dez.2014. DOI:10.5433/2178-8189.2014v18n2p55. 